\title{
Evaluation of the use of an alkali modified fly ash as a potential adsorbent for the removal of metals from acid mine drainage
}

\author{
P. K. Sahoo • S. Tripathy $\cdot$ M. K. Panigrahi • \\ Sk. Md. Equeenuddin
}

Received: 21 April 2012 / Accepted: 30 May 2013/Published online: 14 June 2013

(C) The Author(s) 2013. This article is published with open access at Springerlink.com

\begin{abstract}
The coal fly ash (FA), mainly containing high unburnt carbon was modified by alkali hydrothermal treatment. The modified fly ash (MFA) contains lower amounts of $\mathrm{Si}$ and $\mathrm{Al}$ and has a higher surface area and $\mathrm{pH}$ than the untreated fly ash (FA). The objective of this study is to investigate the potential of MFA as a low cost adsorbent material for the removal of $\mathrm{Al}, \mathrm{Fe}, \mathrm{Ni}, \mathrm{Pb}, \mathrm{Zn}$ and $\mathrm{Mn}$ from acid mine drainage (AMD). The effect of dose, contact time and competing cations on the adsorption of metals was investigated. The results showed that the sorption process onto MFA was initially rapid, but slowed down thereafter. The optimum time for metal uptake was 180 min while the optimum dose of MFA for metal removal was $120 \mathrm{~g} / \mathrm{L}$. The adsorption data best fit to the Freundlich isotherm model, which demonstrates that the adsorption process is controlled by the heterogeneous nature of the adsorbent. Adsorption kinetics of $\mathrm{Al}, \mathrm{Fe}, \mathrm{Ni}$, $\mathrm{Pb}$, and $\mathrm{Zn}$ onto MFA follow a pseudo second-order reaction, which implies that chemisorption is the
\end{abstract}

P. K. Sahoo $(\square)$

Vale Institute of Technology - Sustainable Development,

Rua Boa Ventura da Silva, 955, Nazaré, Belém,

Pará 66055-090, Brazil

e-mail: prafulla.sahoo@vale.com; prafulla.iitkgp@gmail.com

P. K. Sahoo $\cdot$ S. Tripathy $(\varangle) \cdot$ M. K. Panigrahi

Department of Geology and Geophysics, Indian Institute of

Technology Kharagpur, Kharagpur 721302, West Bengal, India

e-mail: stripathy@iitbbs.ac.in

\section{S. Tripathy}

School of Earth, Ocean and Climate Sciences, Indian Institute of Technology, Bhubaneswar 751013, India

Sk. Md. Equeenuddin

Department of Mining Engineering, National Institute of

Technology Rourkela, Rourkela 769008, Odisha, India adsorption rate-limiting step for them, while for $\mathrm{Mn}$ it is intra-particle diffusion. Preliminary treatment of real mine drainage from Jaintia Hills coalfield indicates that MFA can be an effective and low-cost adsorbent for the treatment of AMD. The desorption data show that most of the metal ions were substantially desorbed in the acidic media, implying that the adsorbent can be regenerated and reused efficiently.

Keywords Modified coal fly ash - Acid mine drainage . Adsorption · Heavy metals

\section{Introduction}

Acid mine drainage (AMD) resulting from the oxidation of sulfide minerals causes severe environmental pollution of natural watercourses and in turn poses threats to human health (Akcil and Koldas 2006) because of its high concentrations of heavy metals, which are non-biodegradable and non-biocompatible; thus they tend to accumulate in living organisms that leads to various kinds of diseases (Alvarez-Ayuso et al. 2003; Sprynskyy et al. 2006). Generation of AMD around working as well as abandoned multimetal sulfide ore bodies and working coal mines of Tertiary ages is quite extensive throughout the world. Therefore, removal of metals from AMD has become a high priority research area. There are several techniques that have been developed for treatment of AMD, including precipitation, electro-dialysis, ultra-filtration, electrolysis, solvent extraction, biosorption, reverse osmosis, and adsorption, etc. (Mohan and Chander 2006; Ríos et al. 2008; references therein). However, adsorption turns out to be the most preferred one for the removal of metals because of its simplicity and efficient mechanism (Mohan 
and Chander 2006; Heping et al. 2006). The adsorption process becomes more viable on commercial scales when the adsorbents are easily available and economically feasible (Bailey et al. 1999; Ríos et al. 2008; Mohan and Gandhimathi 2009). Coal fly ash is one such suitable adsorbent which is gaining increasing attention because it is the most abundant waste material produced from coalfired thermal power plants (Cho et al. 2005; Montagnaro and Santoro 2009; Mohan and Gandhimathi 2009). Its major chemical components such as alumina, silica, iron oxide, and carbon and physical properties such as porosity, particle size, and surface area make it a potential agent for the adsorption of metals from contaminated water (Cetin and Pehlivan 2007; Ahmaruzzaman 2010). The use of coal fly ash as well as synthetic products such as zeolites manufactured from fly ash, has been widely studied for their adsorption characteristics in the removal of metals from AMD or contaminated water (Moreno et al. 2001a, b; Petrik et al. 2003; Gitari et al. 2006; Perez-Lopez et al. 2007; Ríos et al. 2008). However, the raw fly ash exhibits a low adsorption capacity than synthetic products. In addition, the raw coal ash can be used only when the fly ash is alkaline in nature. Use of coal fly ash containing highunburned carbon can be a more suitable adsorbent for the removal of metals because of its high surface area and low cost (Wang and Zhu 2007).

Tertiary coals of north eastern coalfields of India are well known for their high sulfur content and consequent serious AMD problems (Equeenuddin et al. 2010; Sahoo et al. 2012). Jaintia Hills coalfield is one of them, which is the major coal producing zone in the state of Meghalaya, India. The AMD from this coalfield is strongly acidic ( $\mathrm{pH}$ as low as 1.6) with $\mathrm{SO}_{4}{ }^{2-}$ as the dominant anion and high concentrations of $\mathrm{Fe}$, Al, Mn, Cd, Pb, and Ni (Sahoo et al. 2012), which contaminates the stream water (Fig. 1) used by the surrounding villagers for various purposes including rearing livestocks. Thus, it is essential to develop some cost effective solution to this detrimental effect of AMD. Based on the local geological material, huge quantity of fly ash, which is considered as waste, is being generated in Meghalaya. This ash contains high-unburned carbon particles. Therefore, choice of using this ash as an adsorbent is obvious. In the present work, we investigated the feasibility of using Meghalaya coal fly ash as an adsorbent for the removal of metals from AMD. The adsorption isotherms and adsorption kinetics were studied to model the adsorption process.

\section{Materials and methods}

\section{Experimental materials}

The coal fly ash (FA) was collected from electrostatic precipitators of the Captive thermal power plant (15 MW) situated in Meghalaya, India. The FA was oven-dried at $70{ }^{\circ} \mathrm{C}$, sieved to a particle size of $<500 \mu \mathrm{m}$ and stored in a polythene bag. The raw fly ash has low neutralization potential $(16 \mathrm{~kg}$ $\mathrm{CaCO} 3 \mathrm{eq} / \mathrm{t})$ and poor metals removing ability $(<10 \%$ of metals removed except $\mathrm{Fe}$ and $\mathrm{Al}$ ). To improve the above parameters, the ash was modified using a simple alkali activation technique following Koukouzas et al. (2010). In the modification process, fly ash was mixed thoroughly with $1 \mathrm{M}$ sodium hydroxide $(\mathrm{NaOH})$ solution and then the mixture was kept on a hot plate at $90{ }^{\circ} \mathrm{C}$ for $24 \mathrm{~h}$. After agitation, the solid was recovered by filtration and washed thoroughly with deionized water to remove excess $\mathrm{NaOH}$. The recovered product, termed as modified fly ash (MFA), was dried at $40{ }^{\circ} \mathrm{C}$ for $24 \mathrm{~h}$ and used for the subsequent geochemical characterization and adsorption study.

The $\mathrm{pH}$ of both FA and MFA was determined from their respective slurries prepared using $10 \mathrm{~g}$ ash mixed with $25 \mathrm{~mL}$ of deionized water. The specific surface area was measured using BET (Brunauer-Emmett-Teller) method and the loss on ignition was calculated by heating the pre-
Fig. 1 Contamination of a stream by acid mine drainage around Jaintia coalfield
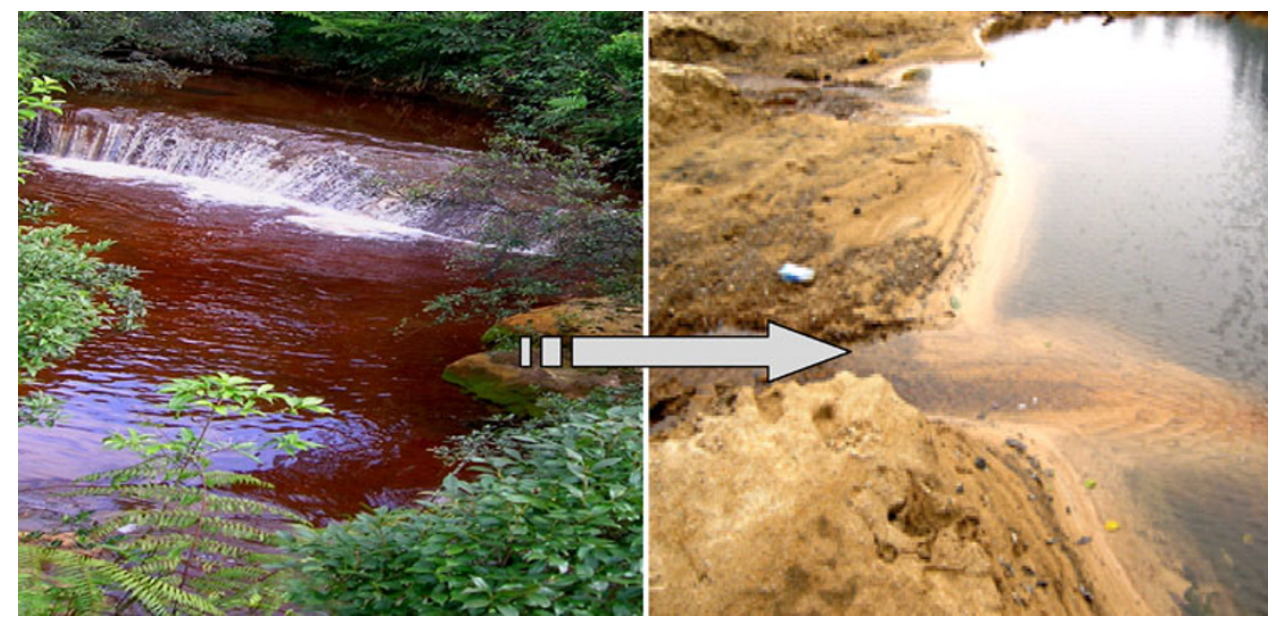
Table 1 Laboratory prepared acid mine water $(\mathrm{pH}=1.65)$

\begin{tabular}{lc}
\hline Parameters & $\mathrm{mg} / \mathrm{L}$ \\
\hline $\mathrm{Al}$ & 119 \\
$\mathrm{Fe}$ & 238 \\
$\mathrm{Zn}$ & 21.6 \\
$\mathrm{Mn}$ & 22 \\
$\mathrm{~Pb}$ & 9.47 \\
$\mathrm{Ni}$ & 14.3 \\
\hline
\end{tabular}

heated sample (Bayat 2002). The point of zero charge $\left(\mathrm{pH}_{\mathrm{zpc}}\right)$ of both types of ash was determined by mixing $0.5 \mathrm{~g}$ of ash with $100 \mathrm{~mL}$ of deionized water in a series of beakers while adjusting the $\mathrm{pH}$ of the slurry from 2.5 to 7.5 using $0.1 \mathrm{M} \mathrm{NaOH}$ or $0.1 \mathrm{M} \mathrm{HCl}$. The mixtures were shaken for $2 \mathrm{~h}$ and the charge potential was measured using zeta potential analyzer (Malvern nano ZS). The mineralogy of the ashes was determined employing Rigaku miniflex $\mathrm{X}$-ray diffractometer (XRD) with $\mathrm{CuK} \alpha$ radiation. Both major and minor element concentrations were obtained using an XRF Spectrometer (Philips PW 2404). The surface morphology of fly ash was observed under a scanning electron microscope (JEOL JSM-5800).

Simulated mine drainage (SMD) was prepared in the laboratory closely resembling the AMD from the Jaintia Hills coalfield by doping various concentrations of metals in the form of their respective sulfate-containing salts. All the reagents used were of analytical grade (MERCK). Deionized water from a MILLI-Q system was used in all the experiments. The chemical composition of SMD is given in Table 1.

\section{Sorption studies}

Batch sorption experiments were carried out by mixing different quantities $(25,50 \mathrm{~g}, 80,120$, and $150 \mathrm{~g}$ to understand the effect of adsorbent dosage; $120 \mathrm{~g}$ for deciphering the kinetics study; and 25, 50, 80, and $120 \mathrm{~g}$ for isotherm study) of MFA in $1000 \mathrm{ml}$ of SMD solutions in separate conical flasks. The mixtures were agitated in a mechanical shaker $(120 \mathrm{rpm})$ for $3 \mathrm{~h}$ at ambient temperature $\left(27 \pm 2{ }^{\circ} \mathrm{C}\right)$ for the effect of dose and isotherm studies, while for kinetics studies, the mixture was agitated for different periods of contact time $(10,30,60,120,180$, $240,300,360$, and $420 \mathrm{~min}$ ); then filtered using Whatman $0.45 \mu \mathrm{m}$ filter paper. The final concentrations of $\mathrm{Fe}, \mathrm{Al}$, $\mathrm{Mn}, \mathrm{Ni}, \mathrm{Zn}$, and $\mathrm{Pb}$ in the aqueous phase were determined using atomic absorption spectrophotometer (AAS). The error in analyzing these cations was within $10 \%$. All the sorption experiments were carried out in duplicate to ensure reproducibility. In each case, the percentage error between the two sets of experiment was within $\pm 10 \%$.
Table 2 Chemical composition of FA and MFA

\begin{tabular}{|c|c|c|c|}
\hline & FA & MFA & Change $(\%)$ \\
\hline \multicolumn{4}{|c|}{ Major component (wt\%) } \\
\hline $\mathrm{SiO}_{2}$ & 46.3 & 38.1 & -17.7 \\
\hline $\mathrm{Al}_{2} \mathrm{O}_{3}$ & 27.6 & 24.5 & -11.2 \\
\hline $\mathrm{Fe}_{2} \mathrm{O}_{3}$ & 5.7 & 5.1 & -10.5 \\
\hline $\mathrm{MgO}$ & 0.3 & 0.28 & -6.6 \\
\hline $\mathrm{CaO}$ & 0.8 & 1.3 & +38.5 \\
\hline $\mathrm{K}_{2} \mathrm{O}$ & 0.46 & 0.42 & -6.5 \\
\hline $\mathrm{Na}_{2} \mathrm{O}$ & 0.67 & 5.85 & +88.5 \\
\hline \multicolumn{4}{|c|}{ Minor elements (ppm) } \\
\hline $\mathrm{Cu}$ & 106 & 101 & -4.7 \\
\hline $\mathrm{Cd}$ & 87 & 65 & -25 \\
\hline $\mathrm{Cr}$ & 61 & 55 & -9.8 \\
\hline $\mathrm{Mn}$ & 80 & 67 & -16.25 \\
\hline $\mathrm{Zn}$ & 220 & 204 & -7.2 \\
\hline $\mathrm{Pb}$ & 119 & 107 & -10 \\
\hline
\end{tabular}

,$+ \%$ of metals added in the MFA;,$- \%$ of metal removed from MFA

Table 3 Physical properties of fly ash untreated (FA) and after modification (MFA)

\begin{tabular}{lcc}
\hline Properties & FA $(\%)$ & MFA $(\%)$ \\
\hline $\mathrm{pH}$ & 5.3 & 11.5 \\
Specific surface area $\left(\mathrm{m}^{2} / \mathrm{g}\right)$ & 24.6 & 47.2 \\
Loss of ignition $(\mathrm{LOI})$ & 17.4 & 20.3 \\
$\mathrm{pH}_{\mathrm{zpc}}$ & 3.6 & 3.7 \\
Particle size $(<75 \mu \mathrm{m})$ & 30 & 28 \\
Particle size $(>75 \mu \mathrm{m})$ & 70 & 72 \\
\hline
\end{tabular}

The adsorption capacity of metals was calculated as follows:

Adsorption $(\%)=\left(C_{\mathrm{i}}-C_{\mathrm{f}}\right) \times 100 / C_{\mathrm{i}}$

where, $C_{\mathrm{i}}$ and $C_{\mathrm{f}}$ are the concentrations of the metal ions in the initial and final solutions, respectively.

The batch adsorption experiments were also conducted with actual acid mine drainage collected from Jaintia coalfield using the optimum dosage $(120 \mathrm{~g} / \mathrm{l})$ of adsorbent (MFA) in 1,000 $\mathrm{mL}$ of solution.

The experimental data were analyzed using adsorption isotherm such as the Freundlich and Langmuir adsorption isotherm and kinetic equations such as pseudo first-order, pseudo second-order and intra-particle diffusion equations.

\section{Desorption experiments}

The desorption experiments were carried out using the metal-loaded MFA, recovered from adsorption experiment, in both acidic and near neutral solution to estimate the metal releasing capacity of MFA. Acidic solution ( $\mathrm{pH} 2$ ) 
Fig. 2 Photomicrographs of cenospheres (a) and porous structure (b) of coal ash
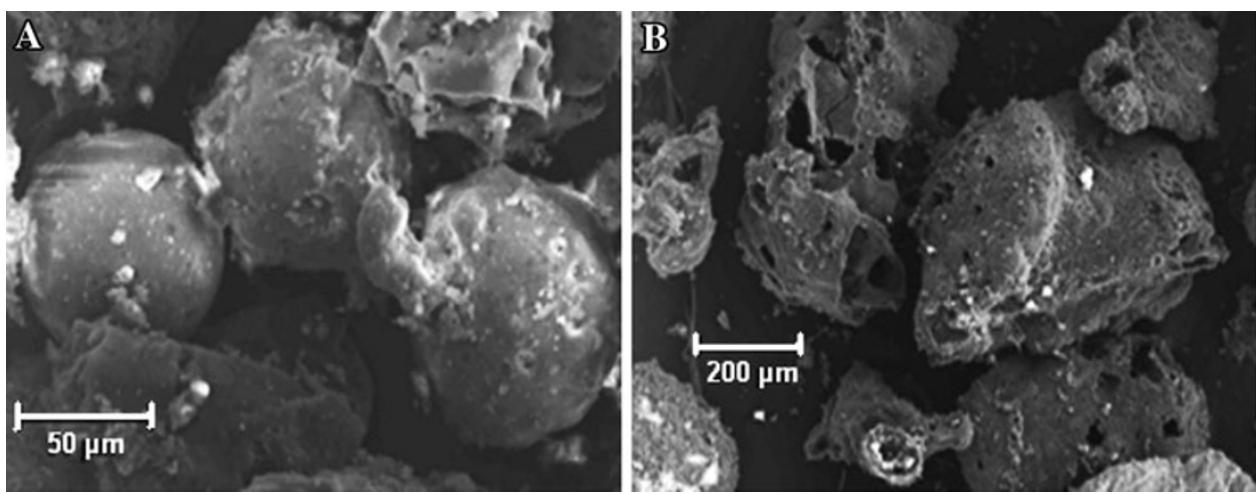

was prepared using $0.1 \mathrm{M} \mathrm{HCl}$ and deionized (DI) water while near neutral solution ( $\mathrm{pH}$ 6.5) was pure DI water. In the experiment, $30 \mathrm{~g}$ of MFA (recovered from adsorption experiment) was treated in $1,000 \mathrm{~mL}$ of solution and shaken at different time intervals for $7 \mathrm{~h}$. At the end of each time interval, the samples were collected, filtered and analyzed for metal concentrations using AAS. The quantity of each metal desorbed from MFA was calculated by the difference between the amount of metal ions adsorbed on the adsorbent (at the equilibrium stage during the adsorption experiments) and the metal ion concentration in desorption medium.

\section{Results and discussion}

\section{Characterization of the materials}

The chemical composition and the physical properties of FA are given in Tables 2 and 3, respectively. The FA is silicoaluminous with $46.3 \% \mathrm{SiO}_{2}, 27.6 \% \mathrm{Al}_{2} \mathrm{O}_{3}, 5.7 \%$ $\mathrm{Fe}_{2} \mathrm{O}_{3}$, and $0.8 \% \mathrm{CaO}$ besides containing trace amounts of $\mathrm{Cu}, \mathrm{Cd}, \mathrm{Cr}, \mathrm{Mn}, \mathrm{Zn}$, and $\mathrm{Pb}$. The ash is acidic in $\mathrm{pH}(\mathrm{pH}$ 5.3) with high surface area $\left(24.6 \mathrm{~m}^{2} / \mathrm{g}\right)$. The fly ash contained very less amount of cenospheres (Fig. 2a) formed by the condensation of aluminous and siliceous droplet in the air, but dominantly contained irregular, porous "sponge like" particles (Fig. 2b) of unburned carbon, which were concentrated in the coarser fraction. The high amounts (approximately $70 \mathrm{wt} \%$ ) of fly ash particles in the coarser fraction (larger than 200 mesh) coupled with high loss on ignition (LOI) indicate the poor combustion efficiency at the thermal power plant. The presence of porous materials and unburned carbon results in high surface area (Wang et al. 2005; Wang and Zhu 2007). The mineralogy of ash includes quartz, anhydrite and hematite as the dominant phases (Fig. 3). In addition, presence of large and irregular background in the diffractogram of ash indicated abundance of glassy and amorphous constituents.

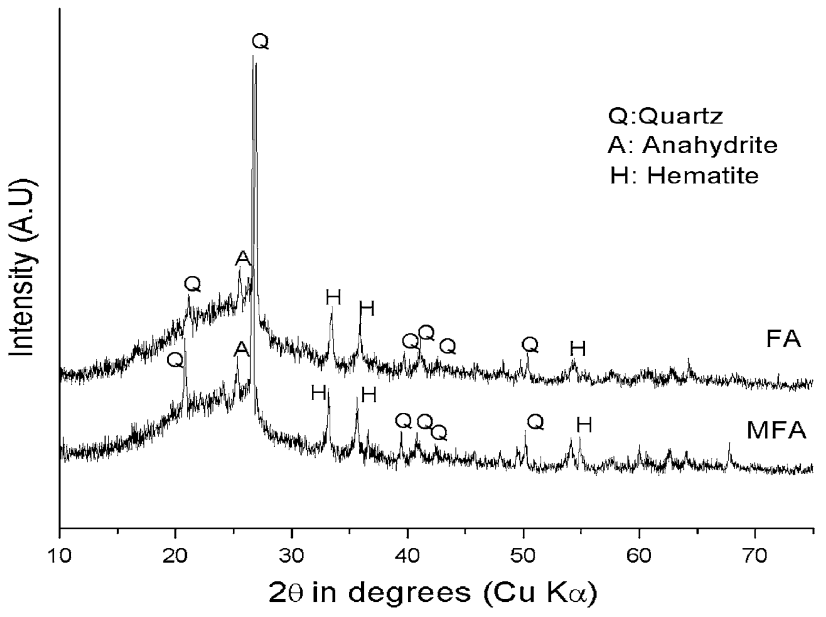

Fig. 3 Diffractrograms of fly ash "untreated (FA) and "modified" (MFA)

The detailed elemental compositions of the MFA are given in Tables 2 and 3. It was observed that while alkali modification reduced the concentrations of major elements, such as $\mathrm{Si}$ and $\mathrm{Al}$ significantly, and resulted in partial leaching of elements viz. $\mathrm{Cd}, \mathrm{Cr}, \mathrm{Mn}, \mathrm{Zn}$, and $\mathrm{Pb}$; the concentration of $\mathrm{Na}_{2} \mathrm{O}$ increased in the MFA. The lower $\mathrm{Si}$ and $\mathrm{Al}$ concentrations in MFA indicate that MFA can be a better sorbent than raw ash for adsorption of metals, because the cation exchange capacity and pore volume are inversely related to the $\mathrm{Si}$ and $\mathrm{Al}$ concentrations (Flanigen 1991; Querol et al. 1997). Further, the pH and surface area increased near about twofold in MFA (Table 3). The particle size, particularly coarser fractions $(>75 \mu \mathrm{m})$, is increased in "MFA" than "FA" with increasing surface area and LOI. Although, similar observation was made by Itkos et al. (2010a, b), in this study, higher surface area coupled with higher LOI in "MFA" are due to increase in a portion micropore and loss of mineral matters from ash after alkali treatment. The mineralogy (Fig. 3) and $\mathrm{pH}_{\mathrm{zpc}}$ remained unchanged irrespective of modification. 
Sorption studies

The effects of various parameters such as contact time, adsorbent dose, and $\mathrm{pH}$ on metal adsorption process of the system are discussed below:

\section{Effect of adsorbent dosage}

The effect of adsorbent dosage (MFA) on metal adsorbed was studied by shaking a series of $1,000-\mathrm{mL}$ flasks containing SAMD with different doses of MFA, varying from 25 to $150 \mathrm{~g} / \mathrm{L}$ for $3 \mathrm{~h}$ at $27 \pm 2{ }^{\circ} \mathrm{C}$. For all these runs, initial concentration of metals in SAMD and temperature are fixed. From Fig. 4a, it was observed that the percentage of metal adsorbed gradually increases as the dose of adsorbent increases from 25 to $120 \mathrm{~g} / \mathrm{L}$ and remained constant thereafter. This is probably due to increase in surface area or number of available adsorption sites with increased dosage (Ozacar and Sengil 2005). The increase in metal uptake becomes insignificant at doses above $120 \mathrm{~g} / \mathrm{l}$ as observable in Fig. 4a. The increase in adsorbent dosage in a fixed volume of adsorbate reduces the number of available sites due to decrease in effective surface area (Namasivayam et al. 1998). Gupta and Bhattacharya (2006) reported similar results for $\mathrm{Ni}$ adsorption by ash. The minimum adsorbent dose corresponding to the
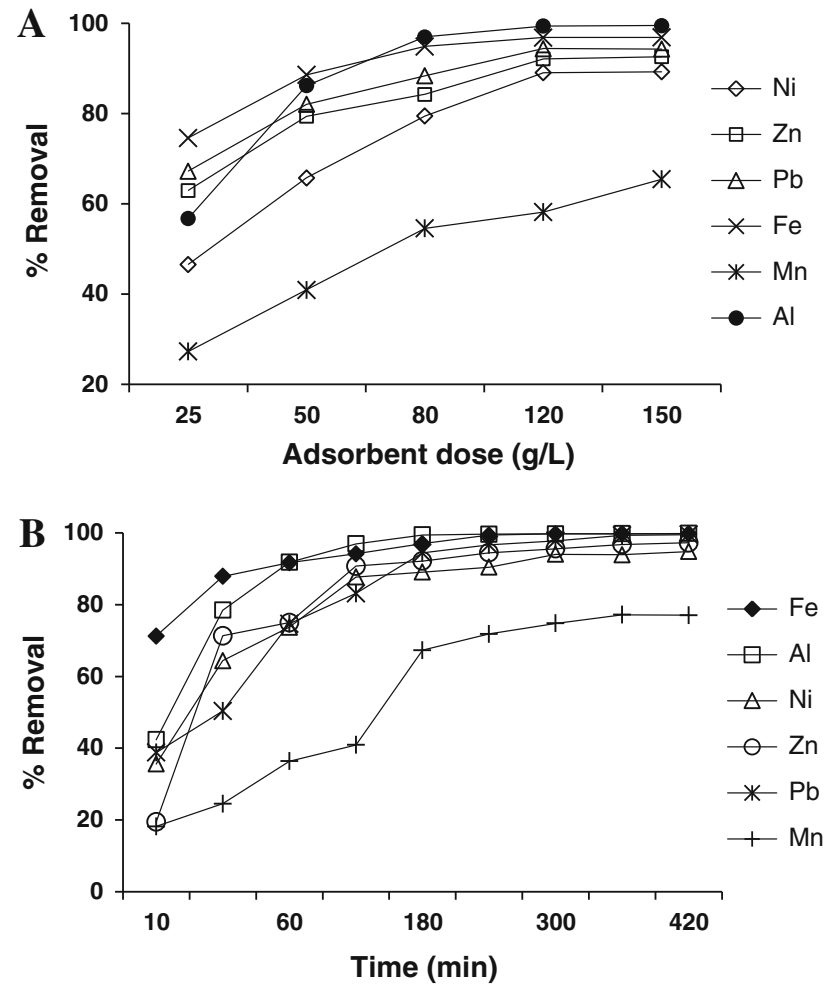

Fig. 4 Effect of the adsorbent dose on metal removal by MFA at 3-h contact time (a) and effect of contact time on metal adsorption onto MFA (b) maximum removal is the optimum dose. Thus, it is found that for the quantitative removal of metals from SAMD, the optimum dose of MFA is $120 \mathrm{~g} / \mathrm{L}$.

Adsorbent recorded a maximum metal removal capacity of $89,92,94,96,60$, and $99 \%$ for $\mathrm{Ni}, \mathrm{Zn}, \mathrm{Pb}, \mathrm{Fe}, \mathrm{Mn}$, and $\mathrm{Al}$, respectively, at optimum dosage $(120 \mathrm{~g} / \mathrm{L})$ and $180 \mathrm{~min}$ contact time. The $\mathrm{pH}$ of the adsorbate increased $(\mathrm{pH}$ 2.8-6.6) with adsorbent dose up to $180 \mathrm{~min}$ and remained constant thereafter. This may be due to the basic nature of the adsorbent.

Effect of contact time

In adsorption process, contact time is one of the important parameters that delineate the equilibrium point of metal adsorption and affect the adsorption kinetics. This was studied by shaking a series of $1,000-\mathrm{mL}$ flasks containing SAMD with a fixed dose of MFA $(120 \mathrm{~g} / \mathrm{L})$ at $27 \pm 2{ }^{\circ} \mathrm{C}$. Figure $4 \mathrm{~b}$ depicts that the adsorption is heterogeneous with initial rapid rate followed by slower rates. Maximum removal of metals happened within $180 \mathrm{~min}$ of agitation and subsequently remained almost constant (Fig. 4b). Thus, the effective contact time or equilibrium time taken was 180 min. Within $1 \mathrm{~h}$, more than $90 \%$ of Fe, $70 \%$ of $\mathrm{Zn}, \mathrm{Pb}$, and $\mathrm{Ni}$ and more than $35 \%$ of $\mathrm{Mn}$ were adsorbed. The rapid adsorption rates in the initial hours are likely due to free adsorption sites are more in the initial stage, and the slow adsorption rate in later stage is due to saturation of the active adsorbent sites (Onundi et al. 2010).

\section{Adsorption isotherms models}

Adsorption isotherms describe the surface properties (heterogeneity/homogeneity) of adsorbents. In the present study, the Langmuir and Freundlich adsorption isotherms were used because these two are most widely used models due to their simplicity and ability to describe the experimental data in a wide range of concentrations (Peric et al. 2004).

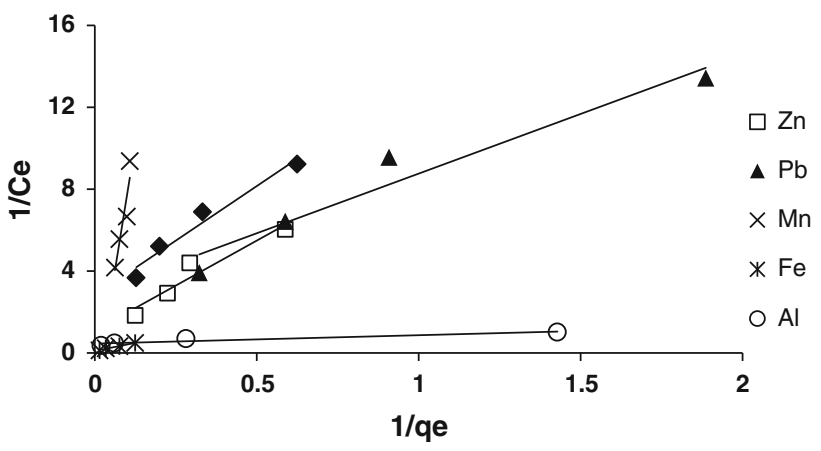

Fig. 5 Langmuir isotherm model for various metals onto MFA 


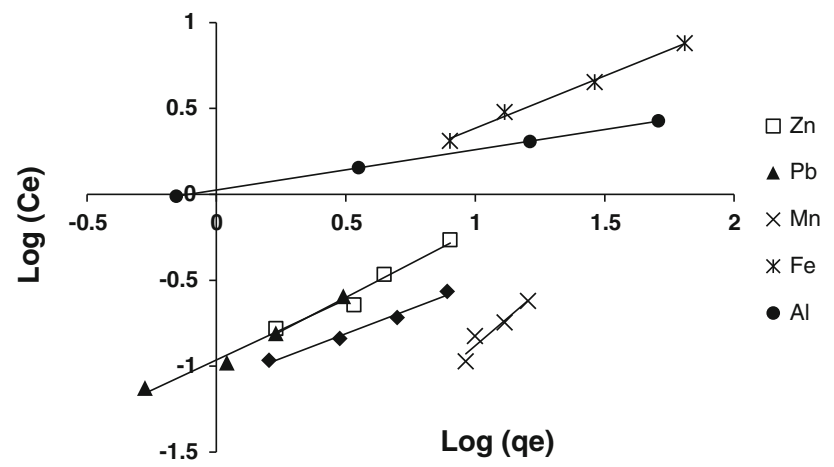

Fig. 6 Freundlich isotherm model for various metals onto MFA

Table 4 Langmuir and Freundlich isotherms parameters for $\mathrm{Al}, \mathrm{Mn}$, $\mathrm{Ni}, \mathrm{Pb}, \mathrm{Fe}$ and $\mathrm{Zn}$ adsorption on MFA

\begin{tabular}{|c|c|c|c|c|c|c|c|}
\hline \multirow[t]{2}{*}{$\begin{array}{l}\text { Metal } \\
\text { ions }\end{array}$} & \multicolumn{4}{|c|}{ Langmuir isotherm } & \multicolumn{3}{|c|}{$\begin{array}{l}\text { Freundlich } \\
\text { isotherm }\end{array}$} \\
\hline & $\begin{array}{l}Q_{\max } \\
\left(\mathrm{mg} \mathrm{g}^{-1}\right)\end{array}$ & $b\left(1 \mathrm{mg}^{-1}\right)$ & $R^{2}$ & $R_{\mathrm{L}}$ & $K_{\mathrm{f}}$ & $n$ & $R^{2}$ \\
\hline $\mathrm{Al}$ & 2.46 & 0.87 & 0.898 & 0.009 & 0.941 & 4.27 & 0.999 \\
\hline Mn & 0.01 & -47 & 0.878 & 0.008 & 0.006 & 0.77 & 0.918 \\
\hline $\mathrm{Ni}$ & 0.093 & 3.759 & 0.961 & 0.018 & 0.08 & 1.75 & 0.985 \\
\hline $\mathrm{Pb}$ & 0.171 & 1.987 & 0.944 & 0.05 & 0.108 & 1.42 & 0.977 \\
\hline $\mathrm{Fe}$ & 0.318 & 32.6 & 0.992 & 0.0012 & 0.598 & 1.64 & 0.994 \\
\hline $\mathrm{Zn}$ & 0.113 & 8.1 & 0.928 & 0.005 & 0.102 & 1.27 & 0.958 \\
\hline
\end{tabular}

The plot of the isotherms is shown in Figs. 5 and 6 and model parameters are contained in Table 4. The results showed that Langmuir isotherm was found to be linear over the concentration studied with low correlation coefficients $\left(R^{2}\right)$ than that of Freundlich isotherm model (Table 4). This indicates that monolayer adsorption occurring at specific homogeneous sites on the adsorbent is not favoring (Langmuir 1916). According to the $Q_{\max }$, sorption onto MFA indicates the following adsorption sequence: $\mathrm{Al}>\mathrm{Fe}>\mathrm{Pb}>\mathrm{Zn}>\mathrm{Ni}>\mathrm{Mn}$.

An essential characteristic of Langmuir isotherm can be presented in a dimensionless constant called separation factor $\left(R_{\mathrm{L}}\right)$. For favorable adsorption $0<R_{\mathrm{L}}<1$; whereas, $R_{\mathrm{L}} \geq 1$ depicts unfavorable and linear adsorption and $R_{\mathrm{L}}=0$ describes unfavorable but irreversible adsorption (Kadirvelu and Namasivayam 2003). From the calculated $R_{\mathrm{L}}$, it is inferred that adsorption of all metals onto MFA is favorable being high in the case of $\mathrm{Al}$.

From Fig. 6 and Table 4, it is observed that the values of $R^{2}$ of Freundlich isotherms for all metals are high except $\mathrm{Mn}$, indicating that the data fit well with the Freundlich isotherm model, giving an expression of surface heterogeneity as well as multilayer of adsorption characteristics (Freundlich 1906). Values of ' $n$ ' between 1 and 10 represent good degree of adsorption (Erdem et al. 2004) and comparing this with values obtained (Table 4), it can be said that the data indicate good adsorption of all metals onto MFA except Mn. Furthermore ' $K_{\mathrm{f}}$ ', a constant related to adsorption capacity, shows the sequence $\mathrm{Al}>\mathrm{Fe}>\mathrm{Pb}>\mathrm{Zn}>\mathrm{Ni}>\mathrm{Mn}$. From the above study, it was found that the adsorption of metals is controlled by the heterogeneous nature of the adsorbent with an exponential distribution of adsorption energy on the surface sites.

Effect of competing cations on adsorption

Keeping in view that the acid mine drainage is multicomponent in nature with various metals in solution at varying concentrations; it is pertinent to observe the influence of competing ions on the individual metal adsorption onto MFA. The adsorption efficiency of both single and multicomponent solutions are compared and presented (Fig. 7). The lowering of adsorption of metals (in $\%$ ) in multicomponent solutions are $0.78,1.4,66,35.9,27$, and 25 for these metals $\mathrm{Fe}, \mathrm{Al}, \mathrm{Mn}, \mathrm{Zn}, \mathrm{Ni}$ and $\mathrm{Pb}$, respectively, compared to their corresponding single component solutions. These values indicate $\mathrm{Fe}$ and $\mathrm{Al}$ are unaffected by competing ions relative to other metals. This is probably due to removal of $\mathrm{Fe}$ and $\mathrm{Al}$ through precipitation rather than adsorption. The adsorptions of other ions were significantly affected suggesting different kinds of adsorption mechanism to be involved in the process (Amarasinghe and Williams 2007). Subsequently, the kinetics of the adsorption process was analyzed.

\section{Adsorption kinetics}

In order to investigate the rate-limiting mechanisms in the adsorption process, the kinetic models, such as the pseudo first-order (Lagergren 1889), pseudo second-order (Ho and McKay 1999) and intra-particular diffusion (Weber and Morris 1963) were tested. These three models are currently widely used for adsorption systems due to its good

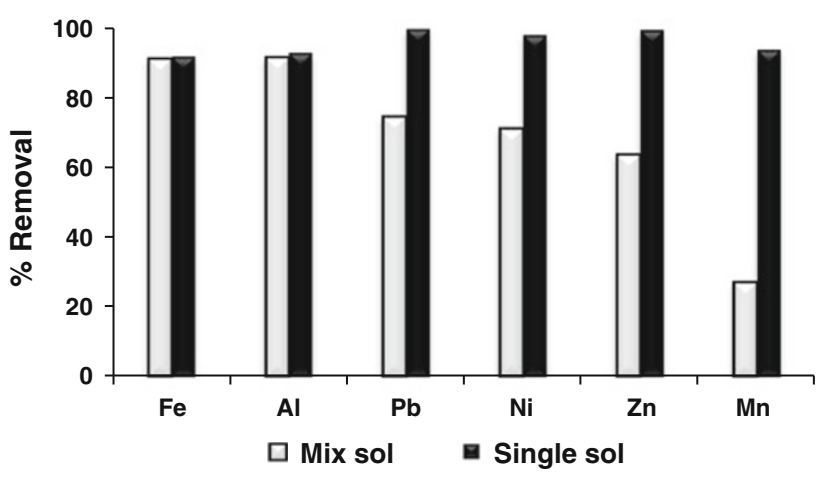

Fig. 7 Comparison of the adsorption of metals from single and multielement solution ( $\mathrm{sol}$ solution) 

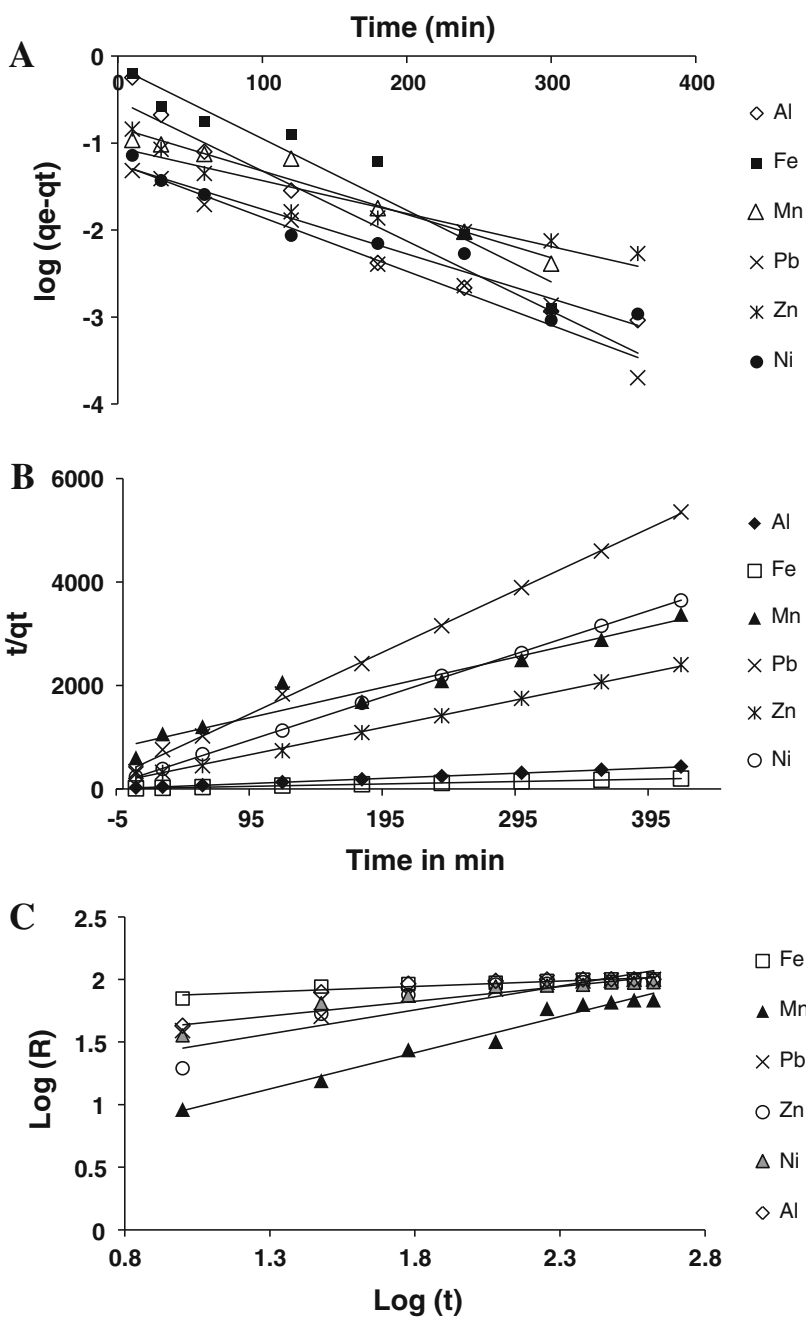

Fig. 8 Pseudo first-order plot (a), pseudo second-order plot (b) and intra-particle diffusion model (c) of various metals onto MFA

representation of the experimental data for most of the adsorbent adsorbate systems.

From the plot (Fig. 8a, b) and the equilibrium parameters calculated thereof (Table 5) for various metals, it was found that the linear correlation coefficient $\left(R^{2}\right)$ of pseudo second-order model for all metals (except $\mathrm{Mn}$ ) is relatively high $\left(R^{2}>0.99\right)$ compared to the pseudo first-order model. Also, the calculated $q_{\mathrm{e}}$ were in good agreement with experimental $q_{\mathrm{e}}$ (Table 5) of pseudo second-order reactions, except for Mn. This shows that except for Mn, the adsorption of $\mathrm{Pb}, \mathrm{Zn}, \mathrm{Ni}, \mathrm{Al}$ and $\mathrm{Fe}$ followed pseudo second-order type reactions indicating chemisorption as the rate-limiting step, indicating that the adsorption capacity is proportional to the active sites on the surface of the adsorbent (Ho and McKay 1999). Kinetic constants generated (Table 5) from the slope and intercept of the plot suggest higher reaction rate and hence greater adsorption with higher $k_{2}$ while lower $q_{\mathrm{e}}$ indicates higher absorption capacity (Mohan and Gandhimathi 2009). Hence, the order of adsorption is $\mathrm{Ni}>\mathrm{Pb}>\mathrm{Zn}>\mathrm{Al}>\mathrm{Fe}>\mathrm{Mn}$.

From Fig. 8c and Table 5, it was observed that intraparticle diffusion model describes Mn better than the others, as the correlation coefficient $\left(R^{2}\right)$ of $\mathrm{Mn}$ for intraparticle diffusion model is higher than pseudo first-order and pseudo second-order kinetic models. Larger value of ' $a$ ' indicates a better mechanism since ' $a$ ' $<0.5$ indicates that the intra-particle diffusion is not the only rate-limiting step (Kobya 2004). From Table 4, it is observed that only Mn exceeded the value of 0.5 , indicating the rate-limiting step may be intra-particle diffusion for it, indicating that a transport process that involves the movement of this ion from the bulk of the solution into the interior pore of the adsorbent (Kaczala et al. 2009).

\section{Mechanism of metal adsorption}

Coal fly ash adsorbs metals mainly due to its carbon content (Wang et al. 2004) besides the functional oxide groups viz. $\mathrm{SiO}_{2}$ and $\mathrm{Al}_{2} \mathrm{O}_{3}$ (Bayat 2002). Silica surface is positively charged in low $\mathrm{pH}$ and negatively charged at high $\mathrm{pH}$ (Mohan and Gandhimathi 2009). The zero point charge $\left(\mathrm{pH}_{\mathrm{ZPC}}\right)$ of silica is generally two. Similarly, $\mathrm{Al}$ and $\mathrm{Fe}$ also develop surface charges depending on the $\mathrm{pH}$. This indicates that silica and alumina in the adsorbent, above their respective $\mathrm{pH}_{\mathrm{ZPC}}$, provide negative charge, which is used as suitable sites to adsorb metal and metal hydroxide on

Table 5 Adsorption kinetic model rate constants for $\mathrm{Al}, \mathrm{Mn}, \mathrm{Ni}, \mathrm{Pb}, \mathrm{Fe}$ and $\mathrm{Zn}$

\begin{tabular}{|c|c|c|c|c|c|c|c|c|c|c|}
\hline \multicolumn{11}{|c|}{ Pseudo first-order pseudo second-order intra-particle diffusion } \\
\hline $\begin{array}{l}\text { Metal } \\
\text { ions }\end{array}$ & $\begin{array}{l}q_{\mathrm{e}(\exp .)} \\
\left(\mathrm{mg} \mathrm{g}^{-1}\right)\end{array}$ & $\begin{array}{l}k_{1} \\
\left(\min ^{-1}\right)\end{array}$ & $\begin{array}{l}q_{\mathrm{e}} \text { (theor.) } \\
\left(\mathrm{mg} \mathrm{g}^{-1}\right)\end{array}$ & $R^{2}$ & $\begin{array}{l}k_{2} \\
\left(\mathrm{~g} \mathrm{mg}^{-1} \min ^{-1}\right)\end{array}$ & $\begin{array}{l}q_{\mathrm{e}} \text { (theor.) } \\
\left(\mathrm{mg} \mathrm{g}^{-1}\right)\end{array}$ & $R^{2}$ & $\begin{array}{l}k_{\text {id }} \\
\left(\mu \mathrm{g} \mathrm{g}^{-1} \min ^{-1 / 2}\right)\end{array}$ & $a$ & $R^{2}$ \\
\hline $\mathrm{Al}$ & 0.98 & 0.018 & 0.31 & 0.93 & 0.104 & 1.014 & 0.99 & 34.0 & 0.19 & 0.76 \\
\hline Mn & 0.124 & 0.012 & 0.15 & 0.95 & 0.041 & 0.171 & 0.93 & 2.7 & 0.58 & 0.99 \\
\hline $\mathrm{Ni}$ & 0.115 & 0.009 & 0.05 & 0.93 & 0.463 & 0.12 & 0.99 & 25.1 & 0.23 & 0.88 \\
\hline $\mathrm{Pb}$ & 0.078 & 0.014 & 0.06 & 0.97 & 0.462 & 0.083 & 0.99 & 22.2 & 0.26 & 0.95 \\
\hline $\mathrm{Fe}$ & 2.11 & 0.019 & 0.75 & 0.93 & 0.076 & 2.140 & 0.99 & 61.0 & 0.085 & 0.89 \\
\hline $\mathrm{Zn}$ & 0.179 & 0.007 & 0.09 & 0.89 & 0.180 & 0.189 & 0.99 & 11.72 & 0.038 & 0.83 \\
\hline
\end{tabular}




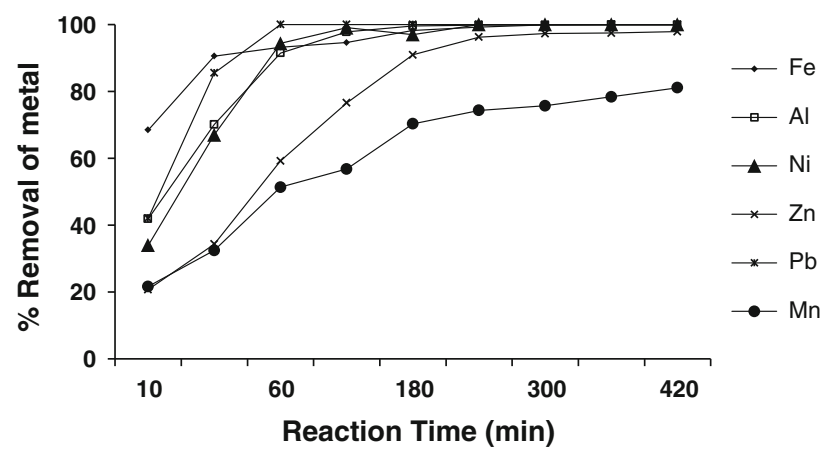

Fig. 9 Removal of metals from real AMD from Jaintia Hills coalfield by MFA

adsorbent surface (Chaiyasith et al. 2006). In this study, the $\mathrm{pH}$ was varied from 2.8 to 6.6. The point of zero charge $\left(\mathrm{pH}_{\mathrm{ZPC}}\right)$ of MFA was 3.7. As the $\mathrm{pH}$ increased greater than 3.7, it can be expected that fly ash surfaces become more negative charged (Eqs. 2 and 3), which allow metals $\left(\mathrm{M}^{+}\right)$ to be complexed at the surface (Eqs. 4 and 5), leading to enhanced cationic metal ions adsorption (Chaiyasith et al. 2006; Wang et al. 2006).

$\equiv \mathrm{SiOH}+\mathrm{OH}^{-} \rightarrow \equiv \mathrm{SiO}^{-}+\mathrm{H}_{2} \mathrm{O}$

$\equiv \mathrm{AlOH}+\mathrm{OH}^{-} \rightarrow \equiv \mathrm{AlO}^{-}+\mathrm{H}_{2} \mathrm{O}$

$2\left(\equiv \mathrm{SiO}^{-}\right)+\mathrm{M}^{+} \rightarrow(\equiv \mathrm{Si}-\mathrm{O}) \mathrm{M}$

$2\left(\equiv \mathrm{AlO}^{-}\right)+\mathrm{M}^{+} \rightarrow(\equiv \mathrm{Al}-\mathrm{O}) \mathrm{M}$

Further, a possible cation-exchange mechanism can be expected in the MFA structure where more $\mathrm{Na}^{+}$sites available for cation exchange as shown below:

$\mathrm{Z}-\mathrm{Na}+\mathrm{M} \rightarrow \mathrm{Z}-\mathrm{M}+\mathrm{Na}^{+}$(where $\mathrm{M}$ represents cations)

Treatment of the natural acid mine drainage

Bases on the above results of metal removal from SMD, the potential of the MFA was also evaluated using acid mine drainage from Jaintia coal field having extremely low $\mathrm{pH}$ (1.6) and high concentrations of $\mathrm{Fe}(243 \mathrm{mg} / \mathrm{L})$, $\mathrm{Al}$
(117 mg/L), Zn (19 mg/L), Ni (3.2 mg/L), Mn (10 mg/L), and $\mathrm{Pb}(1.9 \mathrm{mg} / \mathrm{L})$. The experiment was conducted at the optimum dose $(120 \mathrm{~g} / \mathrm{L})$. Amount of metal removed with respect to time is shown in Fig. 9. It was observed that the maximum amount of metals were removed in the first $3 \mathrm{~h}$ of contact and the removal efficiencies were 98, 99, 97, 90, 100 , and $70 \%$ for $\mathrm{Fe}, \mathrm{Al}, \mathrm{Ni}, \mathrm{Zn}, \mathrm{Pb}$, and $\mathrm{Mn}$, respectively. Hence, it indicates that MFA can be recommended as a suitable material for the treatment of acid mine drainage.

Desorption studies

Desorption studies help in assessing the recovery and reusability of the metal-loaded adsorbent, which in turn may reduce operational cost and protect the environment (Wankasi et al. 2005). In order to assess the metal desorption potential and the recyclability of MFA, desorption reagents of acid and neutral solutions were used at varying contact times. Figure 10 depicts the percentage desorption of the metal ions as a function of time from MFA. This indicates that desorption of metal ions in acidic media (Fig. 10a) was very significant than in neutral media. In acidic media, it was noticed that over $76-98 \%$ of most of the metals, except Mn (57\%), were desorbed at the initial first $3 \mathrm{~h}$, followed by slower rates thereafter. In neutral media (Fig. 10b), a very low amounts (less than $5 \%$ ) of metals, except $\mathrm{Cd}$ (which is less than $8.2 \%$ ), desorbed from the MFA until the end of the study time. This indicates that metal removal involves stable adsorption and complexation of the metal cations on the reactive surfaces of fly ash. The very small percentages of adsorbed metal released during the desorption tests indicated that the metal sequestrated in fly ash remains stable over time. The highest recovery of metals from the MFA in acid medium is may be the fly ash becomes protonated and does not attract the positively charged metal ions, and so the protons replace the bound metal ions. Comparatively, desorption of bound metal ions from the MFA, Cd is greater than other metals in both acidic and neutral media.
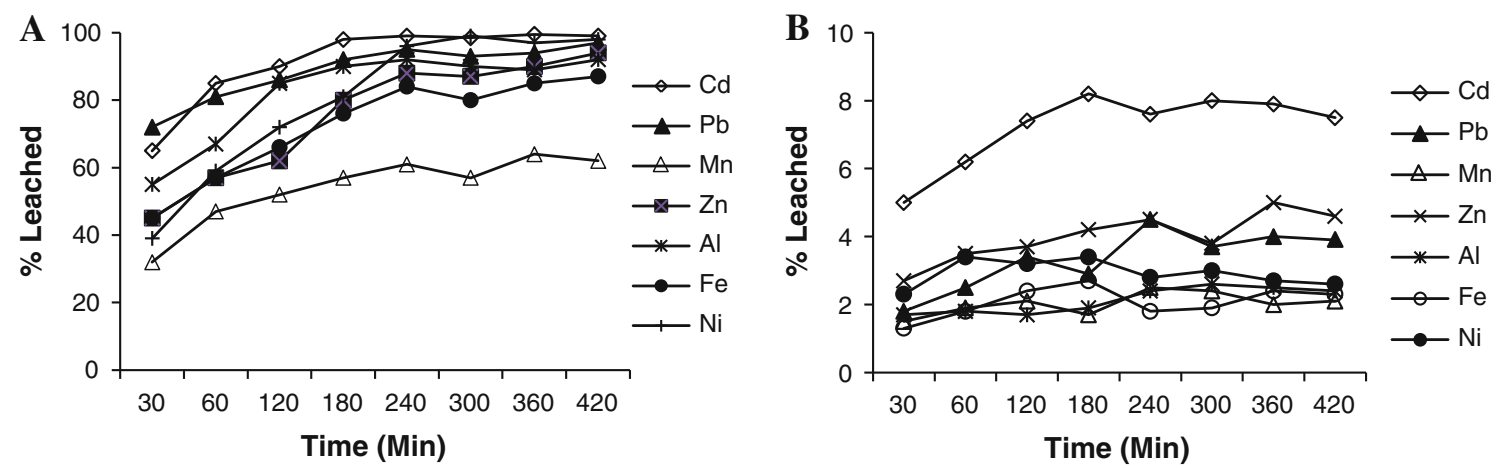

Fig. 10 Desorption of metals from MFA (used) in both acidic (a) and neutral (b) media 


\section{Conclusions}

The MFA has a lower Si and Al concentrations and higher surface area and $\mathrm{pH}$ than the FA. Adsorption of $\mathrm{Ni}, \mathrm{Zn}, \mathrm{Pb}$, $\mathrm{Fe}, \mathrm{Mn}$, and $\mathrm{Al}$ from AMD onto modified coal ash was found to be significant. The adsorption rate of metals was non-uniform with initial rapid rate for the first $3 \mathrm{~h}$ followed by slower rates. The removal of metal ions increases with increasing adsorbent dose; optimum dose of MFA for metal removal was found to be $120 \mathrm{~g} / \mathrm{L}$ with the removal efficiency of 99, 89, 92, 94, 96, and $60 \%$ of $\mathrm{Al}, \mathrm{Ni}, \mathrm{Zn}, \mathrm{Pb}, \mathrm{Fe}$, and $\mathrm{Mn}$, respectively. The results obtained from the isotherm models demonstrated that the adsorption of metals is controlled by the heterogeneous nature of the adsorbent. The adsorption rate-limiting step for $\mathrm{Ni}, \mathrm{Zn}, \mathrm{Pb}, \mathrm{Fe}$, and $\mathrm{Al}$ on MFA is chemisorption or chemical sorption, while for $\mathrm{Mn}$, it is intra-particle diffusion.

Preliminary treatment of actual mine drainage revealed that the modified fly ash has the potential to be used as an effective adsorbent to treat AMD. It can also be used as a substitute of the more expensive adsorbents for the removal of metals from the contaminated water bodies as it is less costly and available locally.

The desorption experiment demonstrated that most of the metal ions were desorbed substantially in the acidic media. The applicability of MFA for metal ion removal from AMD indicates that the adsorbent can be regenerated efficiently so that the bound metal can be recovered and the adsorbent can be reused.

Acknowledgments PKS thanks the Indian Institute of Technology Kharagpur for financial assistance in the form of a research fellowship. Instrumental support for SEM analysis was availed from Central Research Facility of IIT Kharagpur. PKS is also thankful to Dr. S Dutta, State Pollution Control Board, Meghalaya for arranging the fly ash sample.

Open Access This article is distributed under the terms of the Creative Commons Attribution License which permits any use, distribution, and reproduction in any medium, provided the original author(s) and the source are credited.

\section{References}

Ahmaruzzaman M (2010) A review on the utilization of fly ash. Prog Energy Combust Sci 36:327-363

Akcil A, Koldas S (2006) Acid mine drainage (AMD): causes, treatment and case studies. J Clean Prod 14:1139-1145

Alvarez-Ayuso E, Garcia-Sanchez A, Querol X (2003) Purification of metal electroplating waste waters using zeolites. Water Res 37:4855-4862

Amarasinghe BM, Williams WPK (2007) Tea waste as a low cost adsorbent for the removal of $\mathrm{Cu}$ and $\mathrm{Pb}$ from wastewater. Chem Eng J 132:299-309

Bailey SE, Trudy J, Olin TJ, Bricka MR, Adrian DD (1999) A review of potentially low-cost sorbents for heavy metals. Water Res 33:2469-2479
Bayat B (2002) Comparative study of adsorption properties of Turkish fly ashes. The case of nickel(II), copper(II) and zinc(II). J Hazard Mater 95:251-273

Cetin S, Pehlivan E (2007) The use of ash as a low cost, environmentally friendly alternative to activated carbon for the removal of heavy metals from aqueous solutions. Coll Surf A Physicochem Eng Aspects 298:83-87

Chaiyasith S, Chaiyasith P, Septhum C (2006) Removal of cadmium and nickel from aqueous solution by adsorption onto treated fly ash from Thailand, Thammasat. Int J Sci Tech 11: 13-20

Cho H, Oh D, Kim K (2005) A study on removal characteristics of heavy metals from aqueous solution by fly ash. J Hazard Mater 127:187-195

Equeenuddin SkMd, Tripathy S, Sahoo PK, Panigrahi MK (2010) Hydrogeochemical characteristics of acid mine drainage and water pollution at Makum Coalfield, India. J Geochem Explor 105:75-82

Erdem E, Karapinar N, Donat R (2004) The removal of heavy metal cations by natural zeolites. J Coll Interface Sci 280:309-314

Flanigen EM (1991) Zeolites and molecular sieves: a historical perspective. In: Van Bekkum $\mathrm{H}$, Flanigen EM, Jansen JC (eds) Introduction to Zeolite Science and Practice. Elsevier, Amsterdam

Freundlich HMF (1906) Over the adsorption in solution. J Phys Chem 57:385-471

Gitari MW, Petrik LF, Etchebers O, Key DL, Iwuoha E, Okujeni C (2006) Treatment of acid mine drainage with fly ash: removal of major contaminants and trace elements. J Environ Sci Health A Tox Hazard Subst Environ Eng 41:1729-1747

Gupta SS, Bhattacharya KG (2006) Adsorption of Ni(II) on clays. J Coll Interface Sci 295:21-32

Heping C, Loretta LY, John GR (2006) Exploration of remediation of acid rock drainage with clinoptilolite as sorbent in a slurry bubble column for both heavy metal capture and regeneration. Water Res 40:3359-3366

Ho YS, Mckay G (1999) Pseudo second order model for sorption processes. Proc Biochem 34:451-465

Itskos G, Itskos S, Koukouzas N (2010a) Size fraction characterization of highly-calcareous fly ash. Fuel Process Technol 91: $1558-1563$

Itkos G, Koukouzas N, Vasilatos C, Megremi I, Moutsasou A (2010b) Comparative uptake study of toxic elements from aqueous media by the different particle-size-fractions of fly ash. J Hazard Mater 183:787-792

Kaczala F, Marques M, Hogland W (2009) Lead and vanadium removal from a real industrial wastewater by gravitational settling/sedimentation and sorption onto Pinus sylvestris sawdust. Bioresour Technol 100:235-243

Kadirvelu K, Namasivayam C (2003) Activated carbon from coconut coir pith as metal adsorbent: adsorption of $\mathrm{Cd}(\mathrm{II})$ from aqueous solution. Adv Environ Res 7:471-478

Kobya M (2004) Removal of Cr(VI) from aqueous solutions by adsorption onto hazelnut shell activated carbon: kinetic and equilibrium studies. Bioresour Technol 91:317-321

Koukouzas N, Vasilatos C, Itskos G, Mitsis I, Moutsatsou A (2010) Removal of heavy metals from wastewater using CFB-coal fly ash zeolite materials. J Hazard Mater 173:581-588

Lagergren S (1889) Zurtheorie der sogenannten adsorption gelösterstoffe. Kungliga Svenska Vetenskapsakademiens. Handlingar 24:1-39

Langmuir I (1916) The constitution and fundamental properties of solids and liquids. J Am Chem Soc 38:2221-2295

Mohan D, Chander S (2006) Removal and recovery of metal ions from acid mine drainage using lignite a low cost sorbent. J Hazard Mater 137:1545-1553 
Mohan S, Gandhimathi R (2009) Removal of heavy metal ions from municipal solid waste leachate using coal fly ash as an adsorbent. J Hazard Mater 169:351-359

Montagnaro F, Santoro L (2009) Reuse of coal combustion ashes as dye and heavy metal adsorption: effect of sieving and determination on waste properties and adsorption capacity. Chem Eng J 150:174-180

Moreno N, Querol X, Ayora C, Pereira CF, Janssen-Jurkovičová M (2001a) Utilization of zeolites synthesized from coal fly ash for the purification of acid mine waters. Environ Sci Technol 35:3526-3534

Moreno N, Querol X, Ayora C, Alastuey A, Fernández-Pereira C, Janssen-Jurkovičová M (2001b) Potential environmental applications of pure zeolitic material synthesized from fly ash. J Environ Eng 127:994-1002

Namasivayam C, Prabha D, Kumutha M (1998) Removal of direct red and acid brilliant blue by adsorption on to banana pith. Bioresour Technol 64(1):77-79

Onundi YB, Mamun AA, Khatib MFA, Ahmed YM (2010) Adsorption of copper, nickel and lead from synthetic semiconductor industrial wastewater by palm shell activated carbon. Int $\mathrm{J}$ Environ Sci Tech 7:751-758

Ozacar A, Sengil IA (2005) Adsorption of metal complex dyes from aqueous solutions by pine sawdust. Bioresour Technol 96: 791-795

Perez-Lopez R, Nieto JM, Almodovar GR (2007) Utilization of fly ash to improve the quality of the acid mine drainage generated by oxidation of a sulfide-rich mining waste: column experiments. Chemosphere 67:1637-1646

Peric J, Trgo M, Medvidovic NV (2004) Removal of zinc, copper and lead by natural zeolite-a comparison of adsorption isotherms. Water Res 38:1893-1899

Petrik LF, White RA, Klink MJ, Somerset VS, Burgers CL, Fey MV (2003) Utilization of South African fly ash to treat acid coal mine drainage, and production of high quality zeolites from the residual solids. In: Proceedings of the international ash utilization symposium, Centre for Applied Energy Research, University of Kentucky, pp 1-26

Querol X, Plana F, Alastuey A, Lopez-soler A, Andres JM, Juan R, Ferrer P, Ruin CR (1997) A fast method of recycling fly ash: Microwave assisted zeolite synthesis. Environ Sci Technol $31: 2527-2532$

Ríos CA, Williams CD, Roberts CL (2008) Removal of heavy metals from acid mine drainage (AMD) using coal fly ash, natural clinker and synthetic zeolites. J Hazard Mater 156:23-35

Sahoo PK, Tripathy S, SkMd Equeenuddin, Panigrahi MK (2012) Geochemical characteristics of coal mine discharge vis-à-vis behavior of rare earth elements at Jaintia Hills Coalfield, Northeastern India. J Geochem Explor 112:235-243

Sprynskyy M, Boguslaw B, Terzyk AP, Namiesnik J (2006) Study of the selection mechanism of heavy metal $\left(\mathrm{Pb}^{2+}, \mathrm{Cu}^{2+}, \mathrm{Ni}^{2+}\right.$ and $\mathrm{Cd}^{2+}$ ) adsorption on clinoptilolite. J Coll Interface Sci 304: $21-28$

Wang SB, Zhu ZH (2007) Humic acid adsorption on fly ash and its derived unburned carbon. J Coll Interface Sci 315:41-46

Wang J, Teng X, Wang H, Ban H (2004) Characterizing the metal adsorption capability of a class F coal fly ash. Environ Sci Technol 38:6710-6715

Wang SB, Boyjoo Y, Choueib A, Ng E, Wu HW, Zhu ZH (2005) Role of unburnt carbon in adsorption of dyes on fly ash. J Chem Technol Biotechnol 80:1204-1209

Wang J, Ban H, Teng X, Wang H, Ladwig K (2006) Impacts of $\mathrm{pH}$ and ammonia on the leaching of $\mathrm{Cu}(\mathrm{II})$ and $\mathrm{Cd}(\mathrm{II})$ from coal fly ash. Chemosphere 64:1892-1898

Wankasi D, Horsfall MJ, Spiff AI (2005) Desorption of $\mathrm{Pb}^{2+}$ and $\mathrm{Cu}^{2+}$ from Nipa palm (Nypa fruticans Wurmb) biomass. Afr J Biotechnol 4:923-927

Weber WJ, Morris JC (1963) Kinetics of adsorption on carbon from solution. J Sanit Eng Div Am Soc Civ Eng 89:31-60 